\title{
No Injuries in European Sea Bass Tetanized by Pulse Stimulation Used in Electrotrawling
}

\author{
M. Soetaert* \\ Institute for Agricultural and Fisheries Research, Animal Sciences-Fisheries, Ankerstraat 1B-8400, Oostende, Belgium; and \\ Department of Pathology, Bacteriology, and Poultry Diseases, Faculty of Veterinary Medicin, Ghent University, \\ Salisburylaan 133B-9820, Merelbeke, Belgium
}

\section{B. Verschueren}

Institute for Agricultural and Fisheries Research, Animal Sciences-Fisheries, Ankerstraat 1B-8400, Oostende, Belgium

\section{A. Decostere}

Department of Pathology, Bacteriology, and Poultry Diseases, Faculty of Veterinary Medicin, Ghent University, Salisburylaan 133B-9820, Merelbeke, Belgium

\section{J. Saunders}

Department of Veterinary Medical Imaging and Small Animal Orthopedics, Faculty of Veterinary Medicine, Ghent University, Salisburylaan 133B-9820, Merelbeke, Belgium

\section{H. Polet}

Department of Pathology, Bacteriology, and Poultry Diseases, Faculty of Veterinary Medicine, Ghent University, Salisburylaan 133B-9820, Merelbeke, Belgium; and Institute for Agricultural and Fisheries Research, Animal SciencesFisheries, Ankerstraat 1 B-8400, Oostende, Belgium

\section{K. Chiers}

Department of Pathology, Bacteriology, and Poultry Diseases, Faculty of Veterinary Medicin, Ghent University, Salisburylaan 133B-9820, Merelbeke, Belgium

\begin{abstract}
Electrotrawling using electric pulse stimulation is a promising alternative to beam trawling in the brown shrimp Crangon crangon and Dover Sole Solea solea (also known as Solea vulgaris) fisheries of the North Sea. In the sole fishery, a $40-80-\mathrm{Hz}$ pulse stimulation induces tetany in the muscles, which may result in injuries. Whereas no injuries have been reported in flatfish or selachian sharks and rays, electrically induced spinal injuries have been observed in gadoids such as Atlantic Cod Gadus morhua and Whiting (also known as European Whiting) Merlangius merlangus. This may indicate that fish species with a fusiform shape are more susceptible to electric pulses. Similar variation among species in electrically
\end{abstract}

induced spinal injuries has been observed in freshwater electrofishing, although large variability in vulnerability has been reported among different freshwater fusiform species. Therefore, we aimed to assess the vulnerability of another, nongadoid, fusiform osteichthyan: Sea Bass Dicentrarchus labrax (also known as European Bass Morone labrax). Two length groups of Sea Bass $(31.3 \pm 2.2$ and $42.1 \pm 2.5 \mathrm{~cm}$ ) were exposed to electric pulses as used in commercial electrotrawls targeting Sole $(80$ bipolar pulses per second, $2 \%$ duty cycle). Thereafter, the fish were monitored daily and then euthanized $14 \mathrm{~d}$ after exposure for gross, radiographic, and histologic examination. No injuries were found in fish exposed to the electrical pulses. Differences in vertebral morphology among fusiform species may result in varying vulnerabilities to electrically induced

*Corresponding author: maarten.soetaert@ilvo.vlaanderen.be Received April 24, 2017; accepted November 22, 2017 
spinal injuries. As a result, electrically induced spinal injuries and/or their variability in both marine and freshwater species may be determined by similar morphological parameters.

Electrotrawling with electrical pulses is a very promising alternative to conventional beam trawling, particularly for North Sea fisheries targeting Dover Sole Solea solea (also known as Solea vulgaris) and brown shrimp Crangon crangon. In these so-called "electric pulse trawls," the conventional mechanical stimulation by tickler chains or chain matrices is replaced by electrodes generating an electrical stimulus that causes tetany (Soetaert et al. 2015). The switch from mechanical to electrical stimulation, combined with a lower towing speed that results in a smaller area being trawled, offers four major advantages: fuel savings up to $50 \%$ (van Marlen et al. 2014), reduced physical impact on the sea bottom (Depestele et al. 2015), 16-80\% reductions in benthos discards (Rasenberg et al. 2013; van Marlen et al. 2014), and a 30-50\% decrease in the capture of undersized fish (Rasenberg et al. 2013; van Marlen et al. 2014).

However, concerns have been raised regarding possible negative side effects of these electric pulses on marine organisms, especially since spinal injuries have been observed in gadoids, particularly Atlantic Cod Gadus morhua (van Marlen et al. 2014; de Haan et al. 2016; Soetaert et al. 2016a, 2016b, 2016c). Nevertheless, tetany did not induce severe lesions in flatfish such as Sole (Soetaert et al. 2016b), Dab Limanda limanda (also known as Pleuronectes limanda; de Haan et al. 2015), or Small-Spotted Cat Sharks (also known as Spotted Dogfish) Scyliorhinus canicula (Desender et al. 2017). Based on these results, it seems that osteichthyan fusiform fish are especially vulnerable to injury by electric pulses.

Electrofishing in freshwater makes use of entirely different pulse settings and equipment and aims for a different reaction, i.e., involuntary movement toward the electrode (electrotaxis), which may result in tetany or narcosis. Unfortunately, strong tetany of the muscles and associated spinal injuries are a common and well known side effect (reviewed by Snyder 2003), although vulnerability can vary widely both within and among species. The latter even includes large differences among various families with a fusiform body shape, ranging from no or minor injuries in carp (family Cyprinidae) and bass (family Centrarchidae) to very high spinal injury rates in trout, char, and salmon (Salmoninae). This suggests that although vulnerability is partially rooted in morphology, factors other than fish musculature (such as the number of vertebrae) need to be considered when evaluating the effect of electric pulses. At present, no experiments have been performed with marine fusiform osteichthyans other than Atlantic Cod, making it impossible to validate this hypothesis for nongadoid marine fusiform species. Therefore, the aim of the present study was to assess the impact of the tetanizing electric pulses used in electrotrawls targeting Sole on Sea Bass Dicentrarchus labrax (also known as European Bass Morone labrax), which also inhabit the North Sea and thus may be exposed to electric pulses.

\section{METHODS}

We obtained 44 Sea Bass from a commercial farm (Ecloserie Marine de Gravelines, France); they were acclimated for 4 months, fed three times a week (Marico Supreme 16, Coppens International), and divided into two size-groups (group 1: 29 fish, $31.3 \pm 2.2 \mathrm{~cm}[$ mean $\pm \mathrm{SD}$ ]; group 2: $15 \mathrm{fish}, 42.1 \pm 2.5 \mathrm{~cm}$ ). All fish were housed in two tanks $2.75 \mathrm{~m}$ long $\times 1.00 \mathrm{~m}$ wide $\times 1.20 \mathrm{~m}$ high filled with natural seawater in a recirculation system with a common matured and fully functional biological filter. The water depth was $0.9 \mathrm{~m}$ and a $12 \mathrm{~h}$ light : $12 \mathrm{~h}$ dark photoperiod was used. The experiments were approved by the Animal Welfare Ethical Committee of the Institute for Agricultural and Fisheries Research (ID 2011/170).

The Sea Bass were positioned between two wire-shaped electrodes which consisted of two copper conductors $(0.18 \mathrm{~m}, 26 \mathrm{~mm}$ in diameter) lifted from the bottom by two polyvinyl chloride (PVC) discs $(10 \mathrm{~mm}$ width, $70 \mathrm{~mm}$ in diameter) at both ends and separated by an insulator of $0.57 \mathrm{~m}$. Therefore, they were placed with their longitudinal body axis as close to the conductor as possible, while the tip of their snout was located at the front of the first conductor (Figure 1). This was done by holding the fish in a triangular $\mathrm{V}$-shaped cage made of PVC netting as described by de Haan et al. (2016). A 60-V potential difference over the electrodes was applied by a laboratory pulse generator (LPG1, EPLG, Bruges, Belgium) capable of reaching a maximum output of $150 \mathrm{~V}, 280 \mathrm{~A}$, and $42 \mathrm{~kW}$. The generator was equipped with a feedback system to ensure that the output exactly matched the values set. Additionally, the output was double-checked using an oscilloscope (Tektronix TDS 1001B). Sixty V was chosen because this is the upper value achievable in commercial electrotrawls targeting Sole and was used in previous studies (Soetaert et al. 2016a, 2016d). Pulse settings similar to those applied by commercial electric pulse trawls targeting Sole were used: a $60-\mathrm{V}$ bipolar stimulation of rectangular shaped pulses with a duration of $0.25 \mathrm{~ms}$ and a frequency of $40 \mathrm{~Hz}$, resulting in 80 electrical pulses per second (Figure 2). This setting results in a duty cycle of $2 \%$, i.e., 80 pulses of $0.25 \mathrm{~ms}$ per $1,000 \mathrm{~ms}$. The exposure duration was set to $2 \mathrm{~s}$.

All fish were transferred individually with a dip net from the housing tanks to the exposure tank. Fish in group 1 $(n=20)$ and group $2(n=11)$ were exposed according to the same protocol described in Soetaert et al. (2016a). Briefly, each fish was held in a PVC net near the electrode and gently pushed down to hold it near the electrode. When the fish 


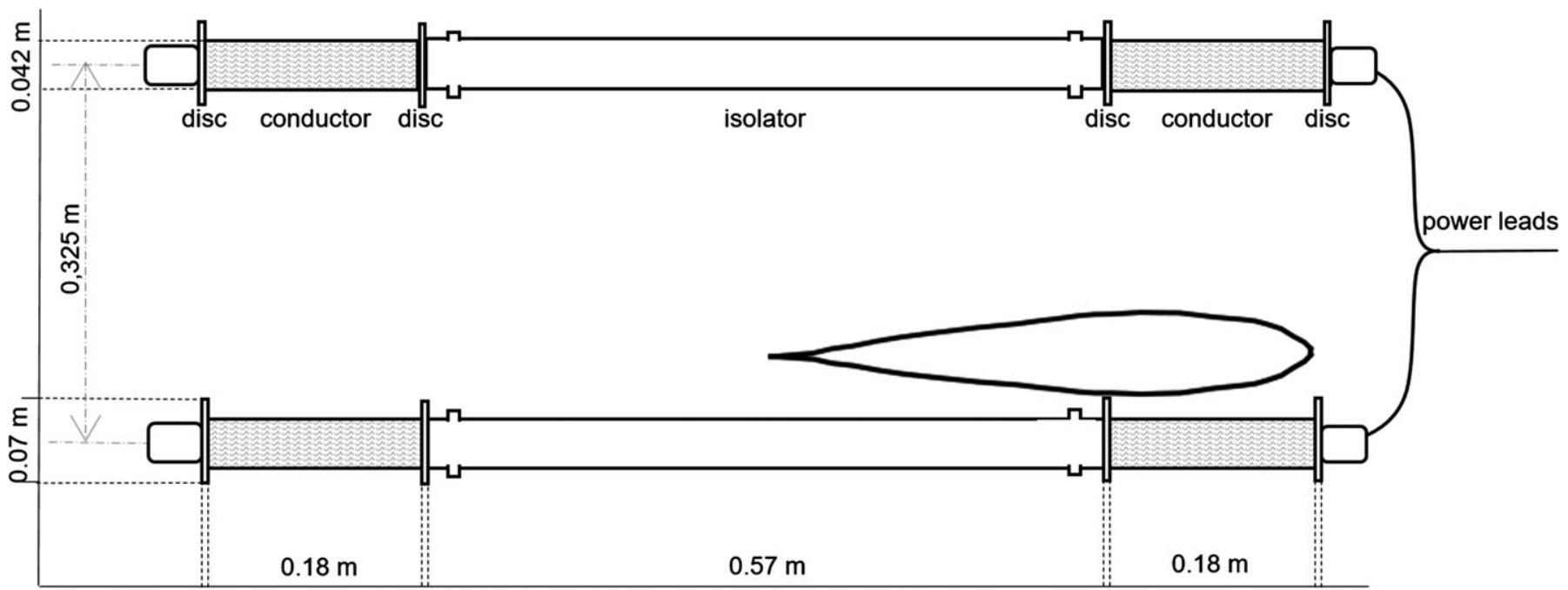

FIGURE 1. Schematic top view of the principal setup in which Sea Bass were exposed to electric pulses. The dashed lines indicate the size of each part.

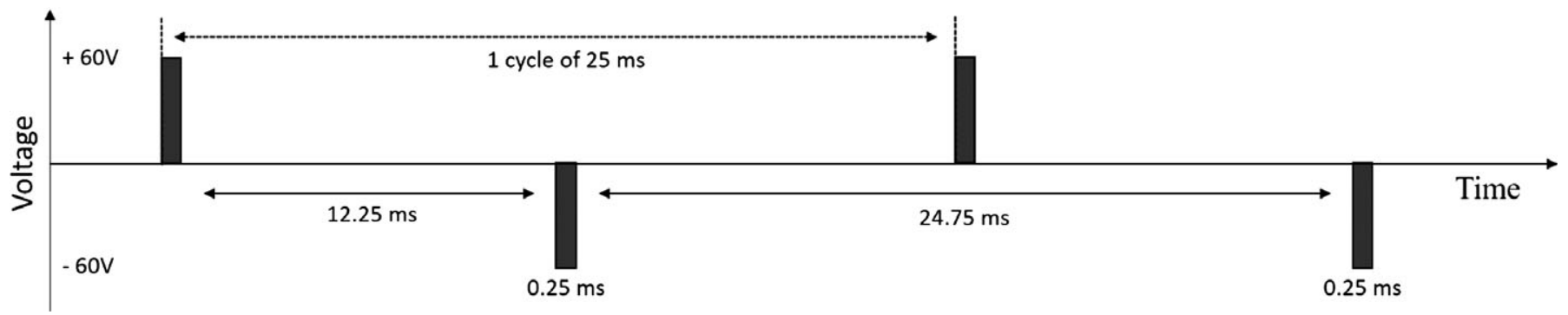

FIGURE 2. Illustration of the pulse stimulation to which Sea Bass were exposed for $2 \mathrm{~s}$ : a $60-\mathrm{V}$ stimulation of 80 bipolar and rectangular shaped pulses per second, each pulse having a duration of $0.25 \mathrm{~ms}$. This results in a frequency of $40 \mathrm{~Hz}$, i.e., 40 identical bipolar cycles of $25 \mathrm{~ms}$.

could not move and was properly positioned parallel to the electrodes, it was exposed to the electric stimulus. All fish showed tetany, and once this was observed the fish were allowed to move rather than being forced to remain in their initial position. Then, the fish were held in the netting material for $15 \mathrm{~s}$, tagged (Floy tag) in the first dorsal fin, and transferred to their housing tanks. The remaining fish (9 in group 1, 4 in group 2) were treated similarly but were not exposed and served as controls. All fish were monitored daily, fed three times a week and sacrificed 2 weeks later. Then they were necropsied and examined for external and internal lesions, particularly spinal injuries that might have occurred during tetany. Their length, total weight, and somatic weight (eviscerated fish $\left[W_{s}\right]$ ) were recorded. The $W_{s}$ values were used to calculate Fulton's condition factor $(K)$ for each fish, i.e.,

$$
K=100 \cdot W_{s} / L^{3},
$$

where $L$ is length (Bagenal 1978). Additionally, internal organs were examined for lesions, and samples of gill, dorsal muscle (base of the third dorsal fin), heart, liver, spleen, gut, and kidney were collected and processed for histological examination and comparison with the control animals, as described in Soetaert et al. (2016a). After necropsy, fish carcasses were labelled and frozen, and lateral and dorsoventral radiographs with X-rays $(60 \mathrm{kV}, 12.5 \mathrm{mAs})$ were taken at Ghent University (EDR6 CANON, type XCDI-50G, flat panel detector; scintillator and amorphous silicon sensor LANMIT 4, Santa Clara, California). All photographs were examined to detect possible malformations, fractures, or luxations, and the number of vertebrae was determined.

\section{RESULTS}

When transferred to the exposure tank, fish exhibited slow swimming behavior in the netting material, mostly pressing their noses to the ends of the net. Immediately after initiation of the electric pulses, all exposed Sea Bass showed tetany. In all but one fish from each group, this was accompanied by distended opercula over the entire exposure time. No 
bending of the body was observed. In the first seconds following exposure, all Sea Bass exhibited an escape reaction and swam away from the point of exposure. This reaction varied between a short $(2 \mathrm{~s})$ of swimming behavior at low or moderate speed $(<1$ tail beat per second) to a more intense $5 \mathrm{~s}$ of agitated swimming, during which some fish tried to jump out of the netting material. Control fish behaved the same as exposed fish during and after restraint but did not exhibit any escape behavior. When released into the housing tanks, all fish returned to their normal swimming behavior.

During the 2-week observation period, none of the fish died and all demonstrated normal feeding behavior. At necropsy, no external or internal abnormalities were found. All Sea Bass had a full stomach after being fed $24 \mathrm{~h}$ prior to sacrifice. The results with respect to length, total weight, and somatic weight are presented in Table 1. $\mathrm{X}$-ray analysis did not reveal any spinal injuries or acute lesions, but in $15 \%$ of the fish congenital defects such as compressed vertebrae, chronic fractures, and block vertebrae were found (Figure 3). Finally, histological examination did not reveal any abnormalities in the gills, heart, dorsal muscle, gut, spleen, kidney, or liver.

\section{DISCUSSION}

The major aim of this study was to investigate the vulnerability of Sea Bass to electrically induced injuries and to reveal differences in susceptibility among fish species. Exposed fish exhibited tetany on being electrically stimulated, followed by an escape response similar to that reported for Atlantic Cod (de Haan et al. 2016; Soetaert et al. 2016a, 2016b); marine flatfish such as Sole, Dab, and Plaice Pleuronectes platessa (Stewart 1977; Soetaert et al. 2016b); and invertebrates such as brown shrimp $C$. crangon (Soetaert et al. 2014, 2016d).

In the present study, Sea Bass were exposed right near the electrode, where the highest field strengths (37-155 V/m) can be found (de Haan et al. 2016). Nevertheless, no adverse side effects were observed. This accords with the absence of injuries in Sea Bass of 10 and $30 \mathrm{~cm}$ exposed to much weaker field strengths $(9.4-15.1 \mathrm{~V} / \mathrm{m})$ - and thus having much smaller potential for causing harm-in an electrode setup typically used in freshwater electrofishing (D'Agaro and Stravisi 2009). In addition, the histopathological results of the present study did not reveal any microscopic lesions on the gills, muscles, or internal organs, indicating either that no lesions occurred or that they had healed within 2 weeks of exposure. Although the results of this laboratory study are reassuring, caution is still warranted because there may be large variability in vulnerability among fish of different origins (Soetaert et al. 2016a) and a few, statistically significant electrically induced spinal injuries have been observed in freshwater Centrarchidae (Snyder 2003).

The absence of spinal injuries in Sea Bass in this and previous studies stands in contrast to the negative effects observed in gadoids such as Atlantic Cod and Whiting (also known as European Whiting) Merlangius merlangus. Therefore, we postulate that the large interspecies difference in vulnerability to electrically induced injuries observed in freshwater electrofishing may also apply to marine fishes. The differences be caused by a similar set of decisive morphological parameters. First, although all exposed fish clearly demonstrated tetany, indicating that the electric field was able to cause a physical response, the thick ctenoid scales of Sea Bass might shield the electric field more efficiently than the thin cycloid scales of Atlantic Cod, resulting in lower penetration into the fish's body and fewer effects. Second, the difference in vertebral injuries may be related to differences in number of vertebrae, as previously suggested by Soetaert et al. (2015). The lower number (23-25) and thus larger vertebrae of the Sea Bass in the present study contrast with the high number (51-54) of smaller vertebrae of gadoids such as Atlantic Cod (Soetaert et al. 2016a) and Whiting (51-53; Milic and Kraljevic 2011). The possible importance of vertebral morphology as factor in the vulnerability for spinal injuries is further emphasized by the occurrence of electric stunninginduced spinal injuries in Pollock Pollachius virens (52-55 vertebrae) and Atlantic Herring Clupea harengus (53-58

TABLE 1. Means \pm SDs of different physiological parameters at postmortem examination and range of vertebrae counts for small (group 1) and large (group 2) Sea Bass.

\begin{tabular}{|c|c|c|c|c|}
\hline \multirow[b]{2}{*}{ Parameter } & \multicolumn{2}{|c|}{ Group 1} & \multicolumn{2}{|c|}{ Group 2} \\
\hline & Control & Exposed & Control & Exposed \\
\hline Number of fish & 9 & 20 & 4 & 11 \\
\hline Size $(\mathrm{cm})$ & $31.1 \pm 2.1$ & $31.4 \pm 2.2$ & $39.5 \pm 2.9$ & $43.0 \pm 1.5$ \\
\hline Weight (g) & $331.4 \pm 57.9$ & $337.7 \pm 72.6$ & $718.1 \pm 180.1$ & $905.1 \pm 105.0$ \\
\hline Somatic weight (g) & $304.4 \pm 53.8$ & $306.3 \pm 72.6$ & $641.2 \pm 164.0$ & $808.1 \pm 91.0$ \\
\hline Fulton's $K$ & $1.00 \pm 0.05$ & $0.98 \pm 0.10$ & $1.02 \pm 0.06$ & $1.02 \pm 0.11$ \\
\hline Number of vertebrae & $24-25$ & $24-25$ & $24-25$ & $23-25$ \\
\hline
\end{tabular}



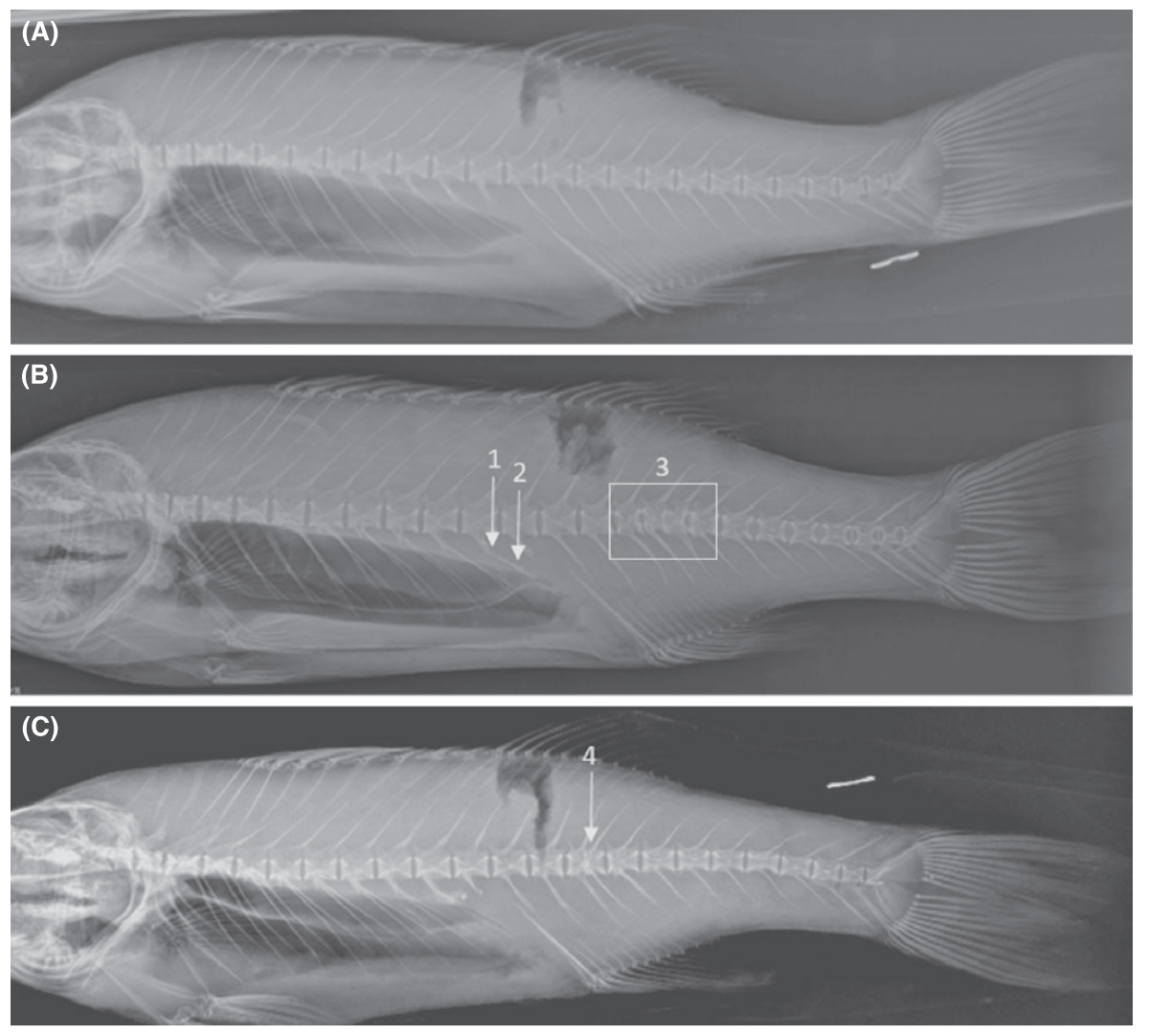

FIGURE 3. X-rays of (A) a normal large Sea Bass and (B) large and (C) small Sea Bass with congenital and/or chronic deformities: $1=$ chronic rib fracture, 2 multiple new bone formation, $3=$ compression of vertebrae with mild secondary degenerative changes at the dorsal aspect, and $4=$ a block vertebrae. The dark blotches at the base of the final dorsal fins were caused by the sampling of muscle tissue for further histological examination. No recent vertebral or spinal injuries resulting from electric-induced tetany were found.

vertebrae) (Roth et al. 2004; Nordgreen et al. 2008). Salmonidae, having a similar morphology as Atlantic Cod, with cycloid scales and a large number of vertebrae (ranging from 55-60 for salmon [Fraser et al. 2015] to 60-66 for trout [Scott and Crossman 1973]), have been reported to be much more susceptible to spinal injuries than other fusiform species such as bass (30-32 vertebrae; Scott and Crossman 1973; Snyder 2003). This suggests that a lower number of larger vertebrae may result in greater mechanical strength and/or robustness of the Sea Bass's vertebral column, making this fish less prone to the development of spinal injuries.

The above hypothesis accounts not only for interspecies differences but also intraspecies variability. Indeed, the most vulnerable (and hence the most studied) species in freshwater and marine electrofishing have shown a highly variable incidence of spinal injuries: $0-78 \%$ for Salmonidae (Snyder 2003) and 0-70\% for Atlantic Cod (Soetaert et al. 2016a). Although extrapolating from and comparing different studies should be done with great care due to the high variability between the experimental setups as well as in the origin and rearing history of the fish, the similar trends between freshwater and marine electrofishing are important and warrant further investigation.
Indeed, decisive morphological parameters determined through the much more extensive freshwater electrofishing research can be used in a mechanistic framework to help predict which marine species are most vulnerable and thus those on which research should be a priority. The possibility of revealing common underlying mechanisms in future research also offers new opportunities for freshwater and marine electrofishing research toward the common goal of reducing electrically induced injuries.

\section{ACKNOWLEDGMENTS}

Maarten Soetaert received a $\mathrm{PhD}$ grant from the Institute for the Promotion of Innovation by Science and Technology in Flanders (IWT-Vlaanderen). Additional support was given by the Flemish Scientific Institute for Agricultural and Fisheries Research (ILVO), which also paid for the finalization of this paper, and the European Fisheries Fund (EVF). F. Delanghe and D. Vuylsteke are thanked for their assistance in taking care of the animals, M. Vercauteren for her help during autopsies, and C. Puttevils and D. Ameye for embedding and processing the samples. Finally, we thank the reviewers who helped 
improve and fine-tune this paper. There is no conflict of interest declared in this article.

\section{REFERENCES}

Bagenal, T. B. 1978. Aspects of fish fecundity. Pages 75-101 in S. D. Gerking, editor. Ecology of freshwater fish production. Blackwell Scientific Publications, Oxford, UK.

D’Agaro, E., and A. Stravisi. 2009. Numerical simulation of electrofishing in seawater. Italian Journal of Animal Science 8(Supplement 2):851-853.

de Haan, D., J. E. Fosseidengen, P. G. Fjelldal, D. Burggraaf, and A. D. Rijnsdorp. 2016. Pulse trawl fishing: characteristics of the electrical stimulation and the effect on behaviour and injuries of Atlantic Cod (Gadus morhua). ICES Journal of Marine Science 73:15571569.

de Haan, D., O. Haenen, C. Chen, A. Hofman, Y. van Es, D. Burggraaf, and E. Blom. 2015. Pulse trawl fishing: the effect on Dab (Limanda limanda). IMARES Report C171/14, Ijmuiden, The Netherlands.

Depestele, J., I. Ana, K. Degrendele, M. Esmaeili, H. Polet, M. Roche, K. Summerbell, L. R. Teal, B. Vanelslander, and F. G. O'Neill. 2015. Measuring and assessing the physical impact of beam trawling. ICES Journal of Marine Science 73:i15-i26.

Desender, M., S. Kaijura, B. Ampe, L. Dumoulin, H. Polet, K. Chiers, and A. Decostere. 2017. Pulse trawling: evaluating its impact on prey detection by small-spotted catshark (Scyliorhinus canicula). Journal of Experimental Marine Biology and Ecology 486:336-343.

Fraser, T. W. K., T. Hansen, M. S. Fleming, and P. G. Fjelldal. 2015. The prevalence of vertebral deformities is increased with higher egg incubation temperatures and triploidy in Atlantic Salmon Salmo salar L. Journal of Fish Diseases 38:75-89.

Milic, D., and M. Kraljevic. 2011. Biometry analysis of the whiting, Merlangius merlangus, (Linneaus, 1758) from the northern Adriatic Sea. Acta Adriatica 52:125-136.

Nordgreen, A. H., E. Slinde, D. Moller, and B. Roth. 2008. Effect of various electric field strengths and current durations on stunning and spinal injuries of Atlantic Herring. Journal of Aquatic Animal Health 20:110-115.

Rasenberg, M., H. van Overzee, F. Quirijns, M. Warmerdam, B. van Os, and G. Rink. 2013. Monitoring catches in the pulse fishery. IMARES Report C122/13, Wageningen, The Netherlands.
Roth, B., D. Moeller, and E. Slinde. 2004. Ability of electric field strength, frequency, and current duration to stun farmed Atlantic Salmon and Pollock and relations to observed injuries using sinusoidal and square wave alternating current. North American Journal of Aquaculture 66:208-216.

Scott, W. B., and E. J. Crossman. 1973. Freshwater fishes of Canada. Fisheries Research Board of Canada, Bulletin 184.

Snyder, D. E. 2003. Electrofishing and its harmful effects on fish. U.S. Geological Survey, Information and Technology Report USGS/BRD/ ITR-2003-0002, Denver.

Soetaert, M., K. Chiers, L. Duchateau, H. Polet, B. Verschueren, and A. Decostere. 2014. Determining the safety range of electrical pulses for two benthic invertebrates: brown shrimp (Crangon crangon L.) and ragworm (Alitta virens S.). ICES Journal of Marine Science 72:973980.

Soetaert, M., D. de Haan, B. Verschueren, A. Decostere, V. Puvanendran, A. Mortensen, J. Saunders, A. Van Caelenberge, H. Polet, and K. Chiers. 2016a. Host-determined variability in occurrence of electric-induced effects in Atlantic Cod (Gadus morhua L.). Marine and Coastal Fisheries: Dynamics, Management, and Ecosystem Science [online serial] 8:412-424.

Soetaert, M., A. Decostere, H. Polet, B. Verschueren, and K. Chiers. 2015. Electrotrawling: a promising alternative fishing technique warranting further exploration. Fish and Fisheries 16:104-124.

Soetaert, M., A. Decostere, B. Verschueren, J. Saunders, A. Van Caelenberge, V. Puvanendran, A. Mortensen, L. Duchateau, H. Polet, and K. Chiers. 2016b. Side effects of electrotrawling: exploring the safe operating space for Dover Sole (Solea solea L.) and Atlantic Cod (Gadus morhua L.). Fisheries Research 177:93-103.

Soetaert, M., H. Lenoir, and B. Verschueren. 2016c. Reducing bycatch in beam trawls and electrotrawls with (electrified) benthos release panels. ICES Journal of Marine Science 73:2370-2379.

Soetaert, M., B. Verschueren, K. Chiers, L. Duchateau, H. Polet, and A. Decostere. 2016d. Impact of repetitive electric exposures on Brown Shrimp (Crangon crangon L.). Marine and Coastal Fisheries: Dynamics, Management, and Ecosystem Science [online serial] 8:404-411.

Stewart, P. A. M. 1977. A study on the response of flatfish (Pleuronectidea) to electrical stimulation. ICES Journal of Marine Science 37:123-129.

van Marlen, B., J. A. M. Wiegerinck, E. van Os-Koomen, and E. van Barneveld. 2014. Catch comparison of flatfish pulse trawls and a tickler chain beam trawl. Fisheries Research 151:57-69. 